\title{
I. IMUNOLOGIA DA REPRODUÇÃO HUMANA
}

\author{
IMMUNOLOGY OF HUMAN REPRODUCTION
}

Sulani S. Souza ${ }^{1}$, Júlio C. Voltarelli² \& Rui A. Ferriani ${ }^{3}$

Pós-graduanda na área de Tocoginecologia do Departamento de Ginecologia e Obstetrícia'; Docente do Departamento de Clínica Médica (Disciplina de Imunologia Clínica) ${ }^{2}$; Docente e Chefe do Departamento de Ginecologia e Obstetrícia ${ }^{3}$ da Faculdade de Medicina de Ribeirão Preto da Universidade de São Paulo ${ }^{1,2,3}$

Correspondência: Sulani S. Souza. Departamento de Ginecologia e Obstetrícia da Faculdade de Medicina de Ribeirão Preto da Universidade de São Paulo - Campus Universitário - CEP: 14048-900 - Ribeirão Preto - SP. Fax: (016) 633-9633.

SOUZA SS; VOLTARELLI JC \& FERRIANI RA. I. Imunologia da reprodução humana. Medicina, Ribeirão Preto, 30: 277-288, abr./jun. 1997.

RESUMO: O sistema imunológico, com sua função tradicional de defender o organismo humano contra agressões externas e endógenas, é visto, hoje, num âmbito mais amplo de caráter homeostático. Assim, participa de vários mecanismos fisiológicos, dentre os quais se inclui a reprodução humana, onde tem importante papel desde a deposição dos espermatozóides até o nascimento do feto. Entretanto, pouco conhecimento é disponível a respeito da importância precisa do sistema imunológico nas várias etapas do processo reprodutivo. Nesta revisão, foram considerados vários aspectos imunológicos da reprodução humana e de quadros clínicos correlatos, como o aborto recorrente e a endometriose, além de estratégias terapêuticas, como a fertilização in vitro e a imunoterapia celular.

UNITERMOS: Reprodução. Imunologia. Citocinas. Aborto Recorrente. Endometriose. Fertilização In vitro.

\section{INTRODUÇÃO}

O sistema imunológico é, hoje, reconhecido como de importância vital para o desencadeamento e controle de vários processos fisiológicos e patológicos. Ele apresenta uma íntima interrelação com os sistemas nervoso e endócrino, havendo, entre eles, vários receptores e ligantes em comum. Assim, substâncias características de cada um destes sistemas, como citocinas, neuropeptídeos, neurotransmissores e hormônios, podem ser sintetizadas por todos estes sistemas e modificar determinadas funções e atividades representativas de cada um deles ${ }^{1}$.
Durante os anos 50 e 60, com Ray Owen, Macfarlane Burnet, Peter Medewar, Gustav Nossal e outros autores, os estudos de tolerância imunológica fizeram desabrochar um novo campo do conhecimento, a Imunologia Reprodutiva. Desde então, reconhece-se que, durante o processo reprodutivo, vários fatores imunológicos participam, de forma direta ou indireta, na sobrevida do concepto (Figura 1) $)^{2,3}$.

\section{SISTEMA IMUNOLÓGICO DAS MUCOSAS}

A deposição dos espermatozóides no trato genital inferior faz com que eles entrem em contato 
íntimo com a mucosa vaginal e suscitem o primeiro estímulo à resposta imune durante o processo reprodutivo. A mucosa vaginal, integrante do sistema imunológico das mucosas, é de grande importância para a proteção contra germes transmitidos sexualmente. Neste sistema, ocorre a comunicação de linfócitos, presentes na superfície da mucosa, com outros, encontrados no espaço subepitelial, uma vez que estes linfócitos migram através do sistema linfático ${ }^{4}$. Outros sítios mucosos incluem o trato respiratório, o trato gastrointestinal, as glândulas salivares e mamárias. Assim, os linfócitos podem ser ativados por antígenos apresentados por células especializadas (macrófagos, no endométrio e endocérvix, e células de Langerhans, na vagina e ectocérvix) em um sítio mucoso e serem transportados para outros sítios via circulação linfática. Entretanto, apesar da regular e repetitiva inoculação de espermatozóides que são antigenicamente "estranhos" no trato genital inferior feminino, pequena resposta imunológica local tem sido observada. Alguns fatores podem contribuir para este fato, como a presença de substâncias contidas no ejaculado com ação supressora e a presença de anticorpos antiespermas em 1 a $12 \%$, em mulheres férteis ${ }^{5}$. Do mesmo modo, Wira \& Rossoll, em $1995^{6}$, observaram, em animais, uma menor eficiência na apresentação de antígenos imediatamente antes da ovulação, aparentemente preparando-se para receber o embrião.

O principal anticorpo, em muitas secreções das mucosas, é a imunoglobulina A ( $\operatorname{Ig} \mathrm{A})$, que pode ser transportada por um mecanismo que envolve uma molécula denominada componente secretor (cadeia J). A maior concentração de células plasmáticas secretoras de $\operatorname{IgA}$ tem sido encontrada nas camadas subepiteliais do endocérvix, seguindo-se nas da ectocérvix, vagina e trompas de Falópio. Nestas regiões, aproximadamente $70 \%$ dos plasmócitos são IgA positivos e, destes, 50 a $75 \%$ estão associados com o componente secretor.

Linfócitos T CD8+ são numerosos no epitélio da ectocérvix, vagina e zona de transformação. Tem sido demonstrado que uma integrina, a $\beta 7 \alpha$, é quase exclusivamente expressa nos linfócitos $\mathrm{T}$ residentes na mucosa vaginal e pode ter papel na adesão, modulação e/ou atividade efetora no epitélio mucoso.

Não se pode ignorar os mecanismos de defesa não específicos, como as barreiras físicas formadas pelas células epiteliais e mucina, o $\mathrm{pH}$, a fagocitose por granulócitos ou macrófagos, a liberação de substâncias com propriedades antimicrobianas (oxigênio reativo e proteases) e a presença de fatores que destroem ou inibem o crescimento ou a atividade de bactérias e vírus (zinco, lisozima, transferrina e outros) $)^{2}$.

\section{ENDOMÉTRIO}

O endométrio humano pode ser dividido em duas regiões principais: a basal e a funcional. $\mathrm{Na}$ região basal, observamos caracteristicamente maior expressão de moléculas HLA-DR e de integrinas $\left(\alpha_{1} \beta_{1}, \alpha_{4} \beta_{1}\right.$ e $\left.\alpha_{1} \beta_{2}\right)$, enquanto, na funcional, a proliferação é o aspecto relevante durante a fase proliferativa e secretória precoce do ciclo menstrual. $\mathrm{O}$ anticorpo monoclonal CD45, um marcador inespecífico das linhagens de células linfóides e mielóides, pode ser observado predominantemente na região basal. Durante a fase secretória, particularmente num período mais tardio, existe um aumento no número de células CD45+, algumas das quais expressam receptores para estrogênio. As células CD4+ e CD8+ estão distribuídas em número equivalente no endométrio, de forma isolada ou em aglomerados. Através da síntese de citocinas, estas células linfóides, que correspondem à maioria das células T e expressam a molécula CD3, têm influência direta no estroma adjacente e no epitélio e, provavelmente, podem ser moduladas pelos hormônios esteroidais ${ }^{7}$.

No endométrio de mulheres não grávidas na fase secretória tardia e na decídua, durante o primeiro trimestre da gestação, predomina uma população peculiar de linfócitos, denominada de linfócitos grandes granulares (LGL). Estas células apresentam um fenótipo antigênico não usual (vide abaixo) e correspondem a $70 \%$ das células locais e 5 a $15 \%$ dos linfócitos do sangue periférico. No endométrio, elas expressam marcadores celulares CD2 e CD7 (pré-tímicos), CD56 (marcador NK) e CD38 (linfócito T ativado), mas não têm CD3 e CD5 (marcadores de linfócitos T maduros) e CD16 (RFcIgG de células NK). Os LGL podem ter papel no controle da implantação e na transformação da vasculatura uterina pelo trofoblasto ${ }^{8,9}$ (Figura 1). 


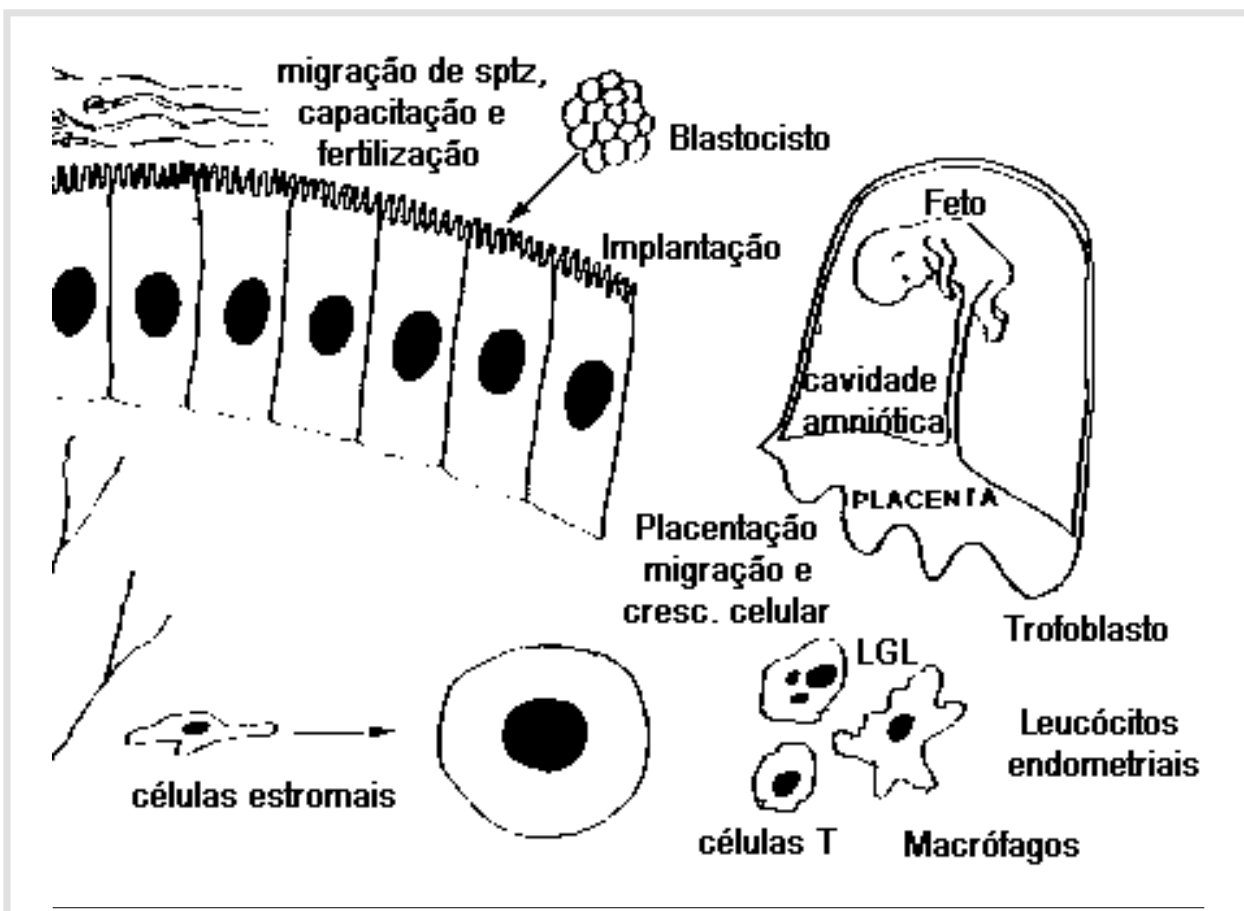

Figura 1 - Fatores imunológicos envolvidos na reprodução humana. Sptz = espermatozóide. $\mathrm{LGL}=$ linfócitos grandes granulares. Modificado de Fay \& Grudzinskas, Hum Reprod, $1991^{3}$.

\section{IMPLANTAÇÃO}

Em torno de seis a sete dias após a fertilização, inicia-se o processo da implantação do embrião. Neste momento, ocorre a aposição, adesão e invasão do trofoblasto ao epitélio uterino, à decídua materna e às artérias espiraladas. $\mathrm{O}$ sucesso da implantação dependerá de uma comunicação apropriada entre blastocisto e endométrio e de um útero adequadamente preparado pela ação hormonal, principalmente da progesterona. A interação blastocisto-endométrio está, pelo menos em parte, sob controle de mediadores imunológicos como as citocinas. Tanto o blastocisto quanto o endométrio apresentam receptores para citocinas e são capazes de produzi-las. A expressão, no endométrio materno, de pelo menos três citocinas parece ser fundamental para a implantação: o fator estimulador de colônias (CSF-1), o fator inibidor de leucemia (LIF) e a interleucina 1 (IL-1 $)^{10}$.

- O CSF-1 é uma glicoproteína que estimula a proliferação e diferenciação das células mononucleares. Esta citocina pode ser encontrada no epitélio uterino e no embrião. Tem sua função regulada pela ação sinérgica do estradiol e da progesterona.

- O LIF é um polipeptídeo que regula, in vitro, a proliferação e diferenciação de células hematopoiéticas, embrionárias, neurais, osteoblásticas e da linhagem endotelial. Esta citocina é produzida, principalmente, na fase secretória do ciclo menstrual ${ }^{11}$, e se expressa também no útero grávido e no blastocisto durante o período de periimplantação, quando sua presença se torna essencial para o sucesso da implantação.

- A IL-1 é uma família de peptídeos que compreende as formas alfa (IL-1 $\alpha$ ) e beta (IL-1 $\beta$ ) e um inibidor, o antagonista do receptor de IL-1 (IL-1ra). Dois receptores para IL-1 foram identificados, o tipo 1 (IL-1R tI), encontrado em muitas células e importante na tradução da ação da IL-1, tendo sua expressão máxima na fase lútea precoce e tardia, e o tipo 2 (IL-1R tII), encontrado, primariamente, nos linfócitos $\mathrm{B}$, neutrófilos e monócitos e cuja função é desconhecida. A bioatividade da IL-1, no soro humano, atinge níveis máximos após a ovulação ${ }^{12}$, na fase lútea média-tardia, enquanto seu antagonista (IL-1ra) está significativamente elevado na fase folicular (Figura 2). A IL-1 é encontrada nos macrófagos e nas células endoteliais do endométrio humano, pode ser secretada também pelo oócito e pelo embrião no período periimplantação e é também uma eficiente indutora de LIF. 


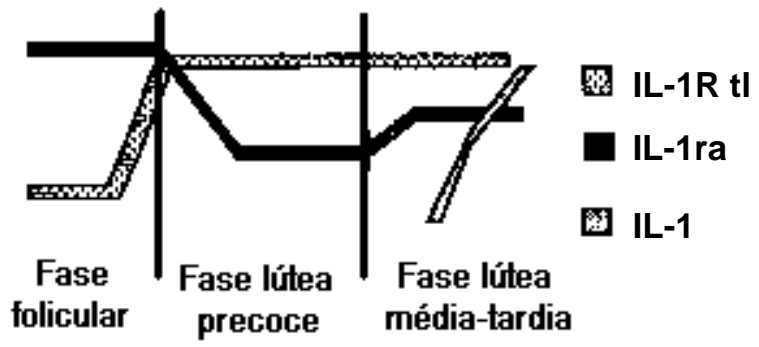

Figura 2 - Dinâmica do sistema da IL-1 no endométrio humano, mostrando que esta citocina atinge níveis máximos na fase lútea média-tardia, enquanto o seu receptor (IL-1RtI) o faz na fase lútea-precoce e média-tardia e o seu antagonista (IL-1ra) tem comportamento inverso ao do receptor. Modificado de Simón et al., Hum Reprod, $1995^{12}$

No período periimplantação, o embrião é capaz de sintetizar e secretar a gonadotrofina coriônica humana (hCG) e o fator ativador de plaquetas derivado do embrião (EDPAF). O hCG apresenta receptores no epitélio uterino, podendo, assim, regular diretamente a função do endométrio e permitir uma implantação normal. Sua detecção só se torna possível com o estabelecimento da comunicação materno-fetal após a implantação. O EDPAF, produzido pelo embrião, estimula a produção do fator de gestação precoce (EPF) pelo ovário, que pode ser observado 6 a 48 horas após a fertilização, o qual passa a ser produzido pelo trofoblasto após a implantação do embrião. O EPF atua sobre os linfócitos, favorecendo a liberação de fatores supressores da resposta imunológica, mas seu papel ainda é muito discutível ${ }^{13}$.

\section{PÓS-IMPLANTAÇÃO}

Após a implantação, células maternas e fetais ficam lado a lado, dentro da decídua materna, sem efeito deletério para nenhuma delas. Alguns fatores podem contribuir para esta coexistência, tais como:

1 - a falta de antígenos principais de histocompatibilidade (HLA) clássicos, expressos na superfície do trofoblasto;

2 - a existência de outros antígenos no trofoblasto como o HLA-C, HLA-G e o antígeno de reação cruzada entre linfócitos e trofoblasto (TLX);

3 - a produção de anticorpos bloqueadores, que incluem os anticorpos anti-HLA, antiidiotípicos e outros;
4 - a síntese de fatores locais supressores, como a prostaglandina $\mathrm{E}_{2}\left(\mathrm{PGE}_{2}\right)$, o fator de crescimento transformador $\beta 2$ (TGF $\beta 2$ ), a progesterona (P4), a substância TJ6 $6^{14}$ e outros;

5 - a síntese de um padrão particular de citocinas do tipo Th2.

\section{TRABALHO DE PARTO}

Diversas cascatas metabólicas, como o eixo hipotálamo-hipófise-adrenal, os sistemas das cicloxigenases, das citocinas, dos hormônios esteroidais e do óxido nítrico contribuem para o desencadeamento e regulação do trabalho de parto. Nenhuma delas parece ser dominante, mas, juntamente com o efeito da anestesia, do estresse e de condições mórbidas associadas, podem explicar um grande número de manifestações clínicas e laboratoriais associadas ao parto normal ou patológico ${ }^{14}$.

O sistema imunológico desempenha um papel central nos dois principais processos fisiológicos envolvidos no trabalho de parto, a contratilidade uterina e a maturação do colo do útero. Assim, o TNF e a IL-1, duas citocinas pró-inflamatórias, estimulam a produção, pelo âmnion e por células endoteliais, de potentes substâncias uterotônicas denominadas endotelinas, as quais, por sua vez, induzem células macrofágicas a produzirem ácido araquidônico, precursor comum das prostaglandinas. Do mesmo modo, toxinas bacterianas, além de TNF, IL-1 e IL-6 encontradas no líquido amniótico durante o parto estimulam a produção de PGE2, PGEI2 e PGE2 $\alpha$ por células do âmnion, córion, endométrio e miométrio, enquanto outras citocinas, como a IL-4 e o TGF- $\beta$ suprimem a produção de prostaglandinas pelos monócitos. Algumas destas prostaglandinas, injetadas por via oral, endovenosa ou diretamente no colo uterino provocam maturação cervical, contrações uterinas e aborto em qualquer estágio da gestação, indicando que estas substâncias devem ter um papel no desencadeamento do parto fisiológico. Por outro lado, o óxido nítrico, que age como relaxante da musculatura lisa, inibindo a produção de endotelina, é sintetizado por células nervosas, sanguíneas e deciduais durante a gestação, reduzindo-se acentuadamente durante o parto, o que lhe sugere um papel supressor da atividade uterina ao longo da gravidez normal.

$\mathrm{O}$ processo de maturação uterina, que ocorre durante o trabalho de parto, pode ocorrer independentemente da contratilidade uterina e possui um importante componente inflamatório. Este se revela 
por edema, vasodilatação e degradação do tecido conjuntivo (principalmente do colágeno e de proteoglucanos) provocado por radicais oxidantes $\left(\mathrm{O}^{-}\right)$e proteases secretados por células fagocitárias, neutrófilos e macrófagos, atraídas ao colo uterino por potentes quimiocinas como a IL-8. Explicam-se, assim, os sinais clínicos de diminuição da consistência, apagamento e dilatação do colo, característicos de uma cervicite fisiológica localizada. A IL-8, a exemplo da IL-1 e do TNF, parece ter ação predominantemente local, pois seus níveis plasmáticos permanecem estáveis durante a gestação, aumentando apenas no líquido amniótico.

Recentemente, uma proteína originada do pulmão fetal, a uteroglobulina, foi encontrada em altos níveis no líquido amniótico, podendo, pois, ter um papel na regulação do parto. Desempenha potente atividade anti-inflamatória e na indução de maturação fetal, à semelhança dos glicocorticóides; estes, entretanto, parecem atuar decisivamente no desencadeamento do parto através do bloqueio de produção da progesterona.

O papel do processo inflamatório no desencadeamento do parto é bem ilustrado pela participação da enzima cicloxigenase-2 (COX-2, induzida, ao con- trário da $\mathrm{COX}-1$, constitutiva), pois camundongos geneticamente deficientes desta enzima ("knock-out") são inférteis e pela observação clínica de que infecções intra-uterinas aceleram o parto, indicando a associação do parto prematuro com processos infecciosos.

A participação dos vários fatores imunológicos na regulação positiva e negativa do trabalho de parto está representada na Tabela I.

Conhecimentos modernos da imunofisiologia e imunopatologia do parto podem auxiliar no entendimento e no diagnóstico de suas complicações e no planejamento mais racional de intervenções terapêuticas. Assim, níveis séricos maternos de IL-6 correlacionam-se com os fetais e com a ocorrência de parto prematuro, enquanto níveis de IL-8 no líquido amniótico constituem o melhor marcador de corioamnionite resistente a medidas tocolíticas. Além disto, anticorpos monoclonais contra moléculas de adesão dos neutrófilos ao endotélio vascular (ELAM) retardam, em modelos experimentais, a maturação cervical e o parto prematuro, aumentando, entretanto, o risco de invasão bacteriana uterina. Este último exemplo ilustra o estágio incompleto destes novos conhecimentos, o que impede, ainda, sua aplicação terapêutica extensiva em seres humanos.

Tabela I - Participação de fatores imunológicos no trabalho de parto

\begin{tabular}{|c|c|c|}
\hline Componente & Papel biológico & Relevância clínica \\
\hline IL-1 & $\begin{array}{l}\text { Estímulo de endotelinas, prostaglandinas, } \\
\text { colagenases e de ACTH }\end{array}$ & $\begin{array}{l}\Uparrow \text { IL-1 em parto normal e infecção ute- } \\
\text { rina; induz aborto }\end{array}$ \\
\hline IL-6 & $\begin{array}{l}\text { Estímulo de prostaglandinas e proteínas } \\
\text { hepáticas de fase aguda }\end{array}$ & $\begin{array}{l}\Uparrow \text { no soro materno e fetal, correlacio- } \\
\text { nado com a duração do parto e com } \\
\text { parto prematuro }\end{array}$ \\
\hline IL-8 & $\begin{array}{l}\text { Quimiotaxia de neutrófilos e ativação de } \\
\text { células endoteliais }\end{array}$ & $\begin{array}{l}\text { 介 no líquido amniótico, no parto, e in- } \\
\text { fecção; correlaciona com corioamnionite }\end{array}$ \\
\hline $\begin{array}{l}\text { Moléculas } \\
\text { de adesão }\end{array}$ & $\begin{array}{l}\text { Aumentadas por citocinas, radicais oxidan- } \\
\text { tes e endotoxinas, induzindo quimiotaxia } \\
\text { e ativação de células fagocitárias e endo- } \\
\text { teliais }\end{array}$ & $\begin{array}{l}\text { Anticorpos anti-ELAM } \Downarrow \text { infiltração de } \\
\text { PMN e maturação do colo e } \Downarrow \text { parto } \\
\text { prematuro }\end{array}$ \\
\hline Óxido nítrico & $\begin{array}{l}\text { Inibição da contratilidade uterina e da ade- } \\
\text { são de leucócitos a células endoteliais }\end{array}$ & $\begin{array}{l}\Downarrow \text { no parto; mantém repouso uterino e } \\
\Downarrow \text { parto prematuro }\end{array}$ \\
\hline $\begin{array}{l}\text { Radicais } \\
\text { oxidantes }\end{array}$ & $\begin{array}{l}\text { Estimulam cicloxigenase e moléculas de } \\
\text { adesão, quebram proteoglicanas, lípides, } \\
\text { enzimas e DNA }\end{array}$ & $\begin{array}{l}\Uparrow \text { câncer de colo em multíparas, cau- } \\
\text { sado por radicais } \mathrm{O}^{-} \text {formados na ma- } \\
\text { turação cervical }\end{array}$ \\
\hline Prostaglandinas & $\begin{array}{l}\text { Induzem contratilidade uterina e matura- } \\
\text { ção cervical }\end{array}$ & $\begin{array}{l}\text { Provocam aborto ou parto em qualquer } \\
\text { fase da gestação }\end{array}$ \\
\hline $\begin{array}{l}\text { Neutrófilos e } \\
\text { macrófagos }\end{array}$ & $\begin{array}{l}\text { Atraídos e ativados no colo uterino por ci- } \\
\text { tocinas e outras substâncias }\end{array}$ & $\begin{array}{l}\text { Induzem cervicite localizada durante } \\
\text { maturação uterina }\end{array}$ \\
\hline $\begin{array}{l}\text { Glicocorti- } \\
\text { cóides }\end{array}$ & $\begin{array}{l}\text { Diminuem a produção de citocinas pró-in- } \\
\text { flamatórias e da progesterona }\end{array}$ & $\begin{array}{l}\text { Induzem maturação fetal e o trabalho } \\
\text { de parto }\end{array}$ \\
\hline
\end{tabular}

ELAM: endothelial-leukocyte adhesion molecule. 


\section{ABORTO RECORRENTE}

Define-se aborto recorrente como três ou mais perdas conceptuais espontâneas e consecutivas antes de 20 semanas de gestação ou de o peso fetal atingir $500 \mathrm{~g}^{15,16}$. Segundo Dudley \& Branch $(1989)^{17}$, sua incidência é inferior a $1 \%$ entre os casais que tentam ter filhos. Podemos denominá-lo primário ou secundário, respectivamente, na ausência ou na presença de um feto vivo viável, precedendo a seqüência de abortos. Esta distinção torna-se impor- tante, em vista de que estes dois grupos parecem apresentar comportamentos epidemiológico e imunológico distintos ${ }^{18}$. Do ponto de vista imunológico, o aborto primário apresenta maior compartilhamento de antígenos HLA, hiporreatividade na cultura mista de linfócitos, ausência de anticorpos bloqueadores e dirigidos contra antígenos paternos, enquanto o secundário apresenta compartilhamento de antígenos HLA e cultura mista de linfócitos normais, presença de anticorpos bloqueadores e contra antígenos paternos (Tabela II).

Tabela II: Classificação e imunopatogênese do aborto recorrente

\begin{tabular}{lll}
\hline & Primário & \multicolumn{1}{c}{ Secundário } \\
\hline Gestação com o mesmo parceiro & sem sucesso & gestação $\rightarrow$ abortos \\
Gestação com outro parceiro & com sucesso & sem sucesso \\
Compartilhamento de antígenos HLA & aumentado & normal \\
Cultura mista de linfócitos & hiporreatividade & normal \\
Anticorpos bloqueadores & ausentes & presentes \\
Anticorpos antilinfócitos & ausentes & presentes \\
Atividade da célula NK & aumentada & - \\
Fenótipo celular & células CD8+ $\uparrow$ & - \\
Auto-anticorpos & presentes & presentes \\
Citocinas & resposta Th1 & - \\
Imunoterapia celular & sucesso & insucesso \\
\hline
\end{tabular}

Apesar de várias causas serem atribuídas ao aborto recorrente (genética, anatômica, hormonal, infecciosa e outras), o fator imunológico parece desempenhar um importante papel na ocorrência desta patologia ${ }^{19,20}$. A coexistência materno-fetal expressa uma resposta orgânica adequada, mas desconhecida, do ponto de vista imunológico. O feto representa um "corpo estranho" ao organismo materno, uma vez que apresenta antígenos de origem paterna distintos daqueles de sua progenitora e que, segundo as lei da Imunologia, suscitam uma resposta imune. De fato, existe, na literatura, um consenso de que, durante a gestação, o organismo materno desenvolve uma resposta imune ao feto, tanto no âmbito local quanto sistêmico e que esta resposta, de modo global, leva à tolerância materno-fetal e não a reações patogênicas. Assim, antígenos fetais são processados pelas células apresentadoras de antígenos (APC) e apresentados às células $\mathrm{T}$, na sua superfície, em associação aos antígenos do complexo principal de histocompatibilidade (MHC).
$\mathrm{Na}$ tentativa de compreender os mecanismos imunológicos envolvidos no aborto recorrente, diversos elementos foram estudados, tais como:

1) Antígenos HLA - Em 1977, Komlos et al. ${ }^{21}$ relataram, pela primeira vez, um elevado índice de compartilhamento do sistema HLA entre os casais com aborto recorrente. Apesar de vários trabalhos realizados na tentativa de elucidar o papel destes antígenos no aborto recorrente ${ }^{22 / 25}$, sabemos que os antígenos HLA-A, -B e -DR não estão expressos na superfície do trofoblasto ${ }^{26}$. Estes antígenos, talvez, pudessem atuar por meio de um desequilíbrio de ligação com outros antígenos relevantes, expressos nos tecidos fetais, como o TLX. Portanto, a tipagem dos antígenos HLA clássicos estaria revelando, indiretamente, alterações no padrão de distribuição destes outros antígenos. De fato, McIntyre $\&$ Faulk (1982) ${ }^{27}$ sugeriram que o compartilhamento de antígenos HLA afeta negativamente a gestação por uma associação com antígenos TLX. Assim, casais que compartilham antígenos HLA 
seriam mais prováveis candidatos a aborto recorrente como resultado da compatibilidade no TLX, pois também teriam antígenos TLX iguais, impossibilitando o desenvolvimento de resposta imune protetora ao feto.

2) Anticorpos citotóxicos - A presença destes anticorpos tem sido considerada por alguns autore ${ }^{28,29}$ como fundamental para que uma gestação subseqüente tenha evolução favorável. Entretanto, Regan $\&$ Braude $(1987)^{30}$ demonstraram que $62 \%$ de mulheres com gestação a termo nunca produziram estes anticorpos.

3) Células "natural killer" (NK) - Aoki et al. $(1995)^{31}$ sugeriram que a avaliação da atividade NK poderia ser um fator preditivo para o aborto, uma vez que as pacientes com aborto recorrente, com níveis elevados desta atividade, tiveram um risco de abortar 3,5 vezes maior do que aquelas com atividade normal. Entretanto, esta observação não foi confirmada em nossa casuística ${ }^{32}$, ainda que com pequeno número de pacientes.

4) Subpopulações celulares linfocitárias - Takakuwa et al. $(1991)^{33}$ e Behar et al. (1993) $)^{34}$ relataram que uma elevação de células CD8+ após imunoterapia celular (transfusão de leucócitos paternos ou de um pool de linfócitos de indivíduos diferentes) poderia beneficiar as pacientes com aborto recorrente, uma vez que induziria um estado de tolerância imunológica, necessária para a manutenção da gestação. Entretanto, Fizet et al. (1990) ${ }^{35}$ e Christiansen et al. (1994) ${ }^{36}$ não confirmaram estes achados.

5) Equilíbrio de citocinas - Hill et al. (1995) ${ }^{37}$ sugerem que uma resposta imune celular tipo Th1 anormal, dirigida a antígenos reprodutivos, seria responsável pela falha reprodutiva nos casos de abortos repetidos, mas esta hipótese também carece de confirmação.

6) Auto-anticorpos - A ativação policlonal das células B parece representar um defeito básico dentro das anormalidades imunológicas, comuns às doenças auto-imunes. As variações individuais na produção destes auto-anticorpos levaram à caracterização de uma síndrome, denominada Síndrome Auto-Imune de Falência Reprodutiva ${ }^{38}$, que pode se manifestar como aborto recorrente, endometriose e/ou infertilidade ${ }^{39}$. Em 1983, Hughes ${ }^{40}$ descreveu a Síndrome de Anticorpos Antifosfolípides (anticoagulante lúpico e anticorpo anticardiolipina), que estavam associados a eventos tromboembólicos, trombocitopenia e complicações obs- tétricas e, principalmente, ao aborto recorrente, revelando o papel patogênico de auto-anticorpos nesta condição.

Em relação à imunoterapia celular para o aborto de repetição, não está estabelecido se realmente beneficiaria as pacientes. Assim, uma metanálise, feita por Jeng et al. ${ }^{41}$, em 1995, mostrou que o efeito deste tratamento para o aborto recorrente mantinha-se inconclusivo mesmo com a utilização dos dados individuais das pacientes. Por outro lado, o procedimento não está isento de riscos, que podem incluir a possibilidade de transmissão de vírus (citomegalovírus, hepatite, AIDS e outros), de sensibilização a células sangüíneas, doenças auto-imunes e retardo de crescimento fetal ${ }^{42}$. Assim, Bux et al. (1992 $)^{43}$ mostraram a possibilidade de aloimunização materna contra granulócitos, aumentando o risco de ocorrência de neutropenia aloimune neonatal. Por outro lado, Carp et al. (1993) $)^{44}$ analisaram a ocorrência de malformações congênitas em pacientes com aborto recorrente e não encontraram incidência significativamente mais elevada do que a da população geral. Não deve ser esquecido, ao se analisar este tipo de terapêutica e outras (imunoglobulina, extrato de trofoblasto, etc.), que a chance de uma gestação a termo, após o terceiro aborto, é de $60 \%{ }^{19,42}$, sem o emprego de qualquer intervenção terapêutica.

\section{ENDOMETRIOSE}

Define-se por endometriose a presença de células endometriais fora da cavidade e musculatura uterinas, tendo sido descrita, pela primeira vez, em 1920, por Sampson, constituindo-se hoje em uma das mais comuns condições ginecológicas. Apesar de mais de $90 \%$ das mulheres apresentarem refluxo menstrual, considerado uma das principais causas da endometriose, apenas uma parte delas desenvolvem a doença. Ela ocorre, geralmente, durante a fase reprodutiva, mas não é raro na adolescência e na menopausa, tendo incidência desconhecida. $\mathrm{O}$ grau de sintomatologia (dismenorréia, dor pélvica e infertilidade) não tem correlação com a gravidade da doença, sendo as pacientes, muitas vezes, assintomáticas. Em trabalho realizado por Jenkins et al. ${ }^{45}$, em 1986, com 182 pacientes, observou-se que o sítio mais comum de implantes era o ovário, em $54,9 \%$ dos casos, seguido pelo ligamento largo $(35,2 \%)$ e os fundos de saco anterior $(34,6 \%)$ e posterior $(34,0 \%)$. 
No tecido endometrióide, observa-se uma concentração de receptores hormonais diferente em relação ao endométrio normal, com predomínio de receptores para progesterona em relação aos para estrógenos, além de modificações nas alterações cíclicas fisiológicas. Estas diferenças podem ser responsáveis pela diversidade de resposta ao tratamento hormonal.

A despeito do grande interesse pelo estudo da endometriose, relativamente pouco se conhece sobre a sua causa, história natural, relação com subfertilidade e, principalmente, sobre sua imunopatogênese. O primeiro relato de alteração da resposta imune na endometriose data de 1980, na literatura médica russa, quando se observou aumento de células B e redução da reatividade de células $T$ nestas pacientes. Neste mesmo ano, Weed \& Arguembourg ${ }^{46}$ observaram a presença de depósitos de complemento (C3) e imunoglobulinas no endométrio acometido. Dois anos mais tarde, Mathur et al. ${ }^{47}$ identificaram a presença de auto-anticorpos contra tecido endometrial e ovariano. Assim, foram geradas duas hipóteses para a imunopatogênese da endometriose:

1 - a de uma doença auto-imune, uma vez que ocorre uma ativação policlonal de células B (aumento de imunoglobulinas e auto-anticorpos), ao lado de outras características de auto-imunidade, como incidência no sexo feminino, ocorrência familiar, dano tecidual inflamatório e envolvimento de múltiplos órgãos;

2 - o processo patológico iniciar-se-ia por uma defi- ciência do mecanismo celular e, secundariamente, ocorreria uma alteração humoral, uma vez que existe um número aumentado de macrófagos no líquido peritonial destas pacientes (Figura 3$)^{48}$. Estas células, basicamente, reconhecem, fagocitam e destroem os microorganismos, mas podem, também, promover o crescimento celular. $\mathrm{Na}$ endometriose, os macrófagos apresentam-se ativados, com um diâmetro celular aumentado, receptores de membrana para outras células, produção aumentada de enzimas (fosfatase ácida, mieloperoxidase, leucina aminopeptidase e outras) e de prostanóides, interleucinas, fatores de crescimento e outras substâncias. Os principais prostanóides presentes no fluido peritoneal são: tromboxano, $o$ metabólito da prostaciclina 6-ceto- $1 \alpha$ e a prostaglandina F2 $\alpha$. Estas substâncias podem alterar a motilidade e velocidade dos espermatozóides, a maturação folicular, a contractilidade uterina, a ação ciliar tubária e o desenvolvimento embrionário. Mais recentemente, tem sido estudada a participação da citotoxicidade celular na patogênese da endometriose. Assim, em 1995, Semino et al. ${ }^{49}$ relataram que a lise celular mediada por célula $\mathrm{T}$, com atividade NK, era aumentada em cultura de células endometriais que modulavam a expressão de antígenos HLA classe I. $\mathrm{O}$ fato de o antígeno HLA-B7 inibir a citotoxicidade NK sugere que o crescimento de células endometriais ectópicas estava sob controle genético.

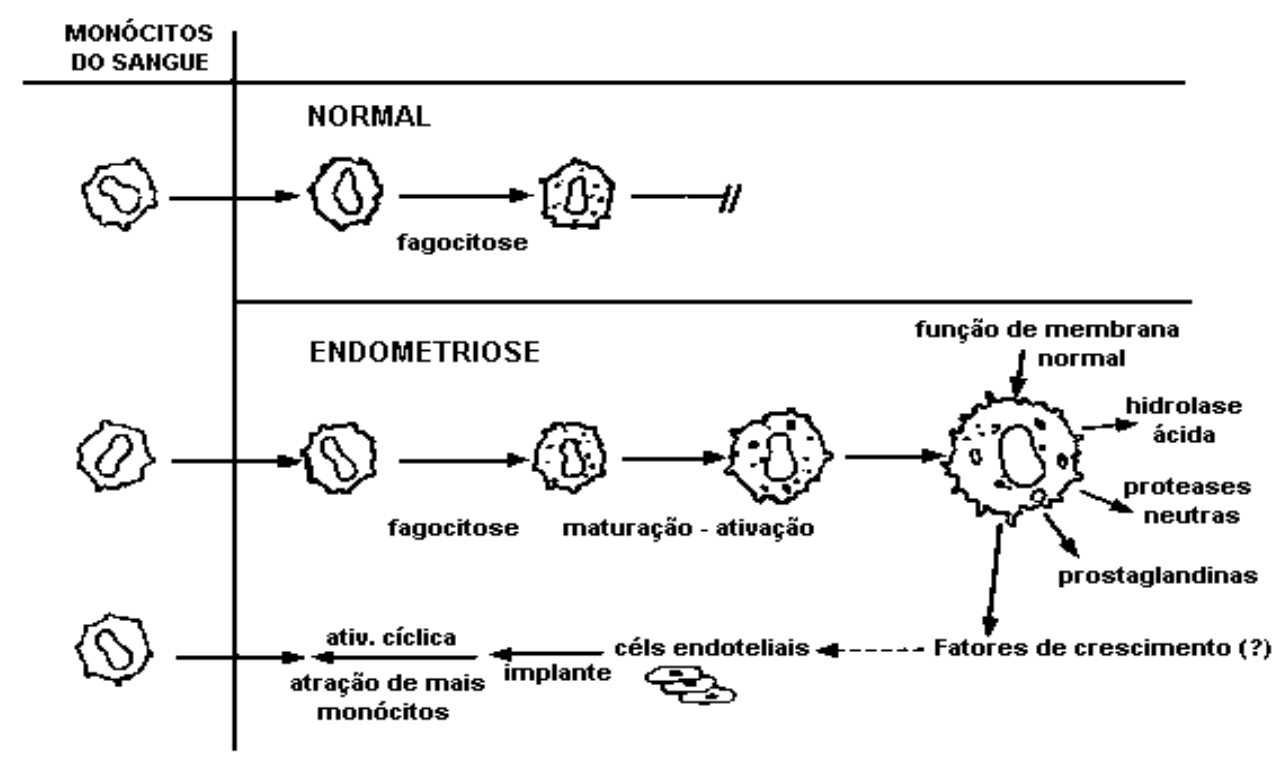

Figura 3 - Mecanismos imunológicos celulares envolvidos na endometriose. Modificado de Halme et al., Am J Obstet Gynecol, $1987^{48}$. 


\section{FERTILIZAÇÃO IN VITRO}

Apesar do avanço dos programas de fertilização in vitro, existem grandes lacunas no conhecimento deste campo, pois pouca melhora se notou, por exemplo, na taxa de implantação do embrião. As razões para a falha no sucesso da implantação do embrião são complexas e multifatoriais ${ }^{50}$. Uma alteração do mecanismo imunológico normal, que envolve a implantação, pode conduzir a falha no estabelecimento de uma gestação clínica, após fertilização in vitro e transferência do embrião, representando apenas uma faceta deste problema.

O fator imunológico pode ter um papel, também, na fertilização e no desenvolvimento da placenta. A presença de auto-anticorpos anormais, em mulheres clinicamente assintomáticas, parece interferir com o sucesso da gestação, após fertilização in vitro (Tabela III). Diferenças na resposta auto-imune entre homens e mulheres são bem reconhecidas. As mulheres tendem a ter uma resposta imune mais vigorosa e maior incidência de doenças auto-imunes. É provável que esta diferença entre sexos seja mediada pela ação dos esteróides sexuais na população de células imunorreativas afetando, particularmente, a produção de anticorpos. A heterogeneidade dos efeitos dos auto-anticorpos, em diferentes mulheres, pode resultar de variações individuais no estímulo para produção destes anticorpos, da afinidade do anticorpo, da presença da glicoproteína $\beta 2$ (ligante específico do anticorpo anticardiolipina) e de fatores genéticos.

Tabela III: Anticorpos possivelmente envolvidos no insucesso da fertilização in vitro

- Anticorpos órgão-inespecíficos

- anticardiolipina

- anticoagulante lúpico

- Anticorpos órgão-específicos

- antitireoidiano

- antiovariano

- antiesperma

Os marcadores de doença auto-imune que foram, estatisticamente, correlacionados com a perda gestacional recorrente e infertilidade inexplicada foram, principalmente, os anticorpos antifosfolípides, que incluem o anticoagulante lúpico a e anticardio- lipina ${ }^{51}$. Em adição, anticorpos antitireoidianos foram encontrados em mulheres aparentemente sadias, mais freqüentemente durante seus anos reprodutivos. Recentemente, estes anticorpos têm sido associados com perda gestacional, independentemente da presença de auto-anticorpos órgão-inespecíficos. Stagnaro-Green et al. $(1992)^{52}$ foram os primeiros a sugerirem que os anticorpos antitireoideanos poderiam ser um marcador periférico para a função de células T anormais. Mais recentemente, Geva et al. (1996) ${ }^{53}$ mostraram resultados que corroboram o fato de estes anticorpos poderem ser um marcador distinto e independente da falha reprodutiva, em pacientes submetidas à fertilização in vitro. Por outro lado, o emprego repetitivo da fertilização in vitro, no tratamento da infertilidade, pode resultar na liberação de uma quantidade significante de antígenos ovarianos, como conseqüência da estimulação hormonal e microtraumas repetitivos, durante a captação do ovócito, ocasionando a liberação de proteínas alteradas das camadas ovarianas internas. Os antígenos ovarianos liberados podem ser capazes de estimular a produção de anticorpos antiovarianos. De fato, Mathur et al. $(1982)^{47}$ demonstraram a ligação destes anticorpos aos ovários e ao endométrio, sugerindo que os anticorpos antiovarianos podem prejudicar o processo de implantação no endométrio. Mesmo considerando que estes auto-anticorpos sejam um possível marcador de falha reprodutiva, ainda são necessárias outras investigações para o entendimento dos mecanismos imunopatológicos deste processo provavelmente auto-agressivo.

Outros anticorpos que podem ter importância na falha do processo reprodutivo são os antiesperma, que podem resultar do comprometimento de fatores inibitórios da resposta imune, presentes no ejaculado, ou de alterações na barreira epitelial da mucosa vaginal. Podem ser dirigidos para a cabeça, porção intermediária ou cauda do espermatozóide e, dentre eles, os primeiros parecem ter maior impacto na infertilidade. Os anticorpos antiesperma podem manifestar seu efeito através da redução do movimento do esperma, da taxa de fertilização e da taxa de divisão celular no pré-embrião ${ }^{54}$. Na mulher, podem estar presentes no soro, predominantemente sob a forma de imunoglobulina $\mathrm{G}$, sem que o seu nível varie com alterações nas concentrações de estrogênio $^{54}$ e no muco cervical, sob a forma de imunoglobulinas G e A. Dentre estas, aproximadamente $70 \%$ da IgA corresponde à subclasse 1 , enquanto IgG4 foi a mais encontrada em associação com alguma $\mathrm{IgG}_{3}{ }^{55}$; 
tanto a $\operatorname{Ig}$ A quanto a IgG4 não são capazes de fixar complemento. Os anticorpos antiesperma podem ocorrer em pelo menos $2 \%$ dos casais fertéis e em 5 a $25 \%$ dos casais infertéis ${ }^{56}$. Segundo Hergshaget et al. ${ }^{57}$, nas mulheres que apresentaram uma proporção significante destes anticorpos no soro, o fluido folicular mostrou títulos de anticorpos significantes em uma maior proporção de casos. No soro de mulheres infertéis, têm sido relatados anticorpos anti-esperma com uma freqüência de 7 e $17 \%{ }^{58}$ o que pode não refletir a presença dos anticorpos nas secreções do trato reprodutivo, como no muco cervical, teoricamente melhor correlacionados à infertilidade, pois são resultantes do sistema imune da mucosa vaginal ${ }^{55}$. Assim, em trabalho realizado por Eggert-Kruse et al. (1993) ${ }^{59}$, observou-se que toda mulher com estes anticorpos no muco cervical apresentava teste pós-coital negativo, isto é, com perda da motilidade dos espermatozóides.

A indução imune dos anticorpos antiesperma pode ser influenciada pelos anticorpos antiidiotípicos. Assim, Naz \& Menge (1994) ${ }^{55}$ observaram que estes anticorpos foram detectados no soro de $71 \%$ das mulheres férteis e estavam ausentes no soro de mulheres virgens. Na mulher, podem ser formados, também, em resposta à administração de esperma por via oral ou retal, enquanto, no homem, podem estar relacionados a obstruções ou injúrias dos ductos reprodutivos. São encontrados em pelo menos $50 \%$ dos vasectomizados, nos indivíduos com HLA tipos A28 e Bw22, em casos de obstrução congênita dos vasos deferentes, em trauma, torção testicular e em homossexuais ${ }^{56}$.

O significado clínico dos anticorpos antiesperma ainda não é claro, uma vez que estudos de seguimento não confirmam uniformemente que as taxas de gestações são menores quando um dos membros do casal mostra o anticorpo ${ }^{60}$. Assim, sua detecção, em casais inférteis, não necessariamente indica infertilidade de causa imunológica ${ }^{61}$.

\section{CONCLUSÃO}

Em conclusão, o sistema imunológico apresenta um importante papel, não apenas como órgão de defesa contra agressões externas, mas também como mediador do equilíbrio dinâmico do organismo. No sistema reprodutor humano, ele tem participação desde a deposição do espermatozóide, passando pela interação entre endométrio e blastocisto, implantação, manutenção da gestação, até o nascimento do feto. Modificações na produção de substâncias próprias deste sistema, de forma direta ou indireta, podem acarretar alterações no processo reprodutivo e, clinicamente, podem manifestar-se como um amplo espectro de patologias, como aborto recorrente, endometriose e/ou infertilidade. Apesar da reconhecida importância do sistema imunológico na reprodução humana, ainda existem grandes lacunas de conhecimento que necessitam de ser preenchidas.

SOUZA SS; VOLTARELLI JC \& FERRIANI RA. Immunology of human reproduction. Medicina, Ribeirão Preto, 30: 277-288, apr./june 1997.

ABSTRACT: The immunological system, which defends the human organism against external and endogenous aggression, is viewed today within a broader homeostatic role. This system also participates in various physiological mechanisms including the reproduction where it plays an important role from the deposition of sperm to the birth of the fetus. However, little is known about the precise importance of the immunological system during the various stages of the reproductive process. In the present review, several immunologic aspects of human reproduction were considered along with correlated clinical conditions such as recurrent abortion and endometriosis and their therapeutic approaches, such as in vitro fertilization and cellular immunotherapy.

UNITERMS: Reproduction. Immunology. Cytokines. Recurrent Abortion. Endometriosis. Fertilization In Vitro. 


\section{REFERÊNCIAS BIBLIOGRÁFICAS}

1 - SOUZA SS; VOLTARELLI JC \& FERRIANI RA. Interação imunoneuroendócrina. Reprod Climat. 11:117-124,1996.

2 - ANDERSON DJ. The importance of mucosal immunology to problems in human reproduction. J Reprod Immunol 31: 3-14, 1996.

3 - FAY TN \& GRUDZINSKAS JG. Human endometrial peptides: a review of their potential role in implantation and placentation. Hum Reprod 6: 1311-1326, 1991.

4 - KELLER MA. Immunology of lactation. In: COULAM CB; FAULK WP \& MCINTYRE JA. Immunological obstetrics, W W Norton \& Company, New York, p. 315-330, 1992.

5 - BECKERMAN KP. Reproduction \& the immune system. In: STITES DP; TERR AI \& PARSLOW TG. Basic \& clinical immunology, 8th, Prentice Hall International, London, p. 552-568, 1994.

6 - WIRA CR \& ROSSOLL RM. Antigen-presenting cells in the female reproductive tract: influence of sex hormones on antigen presentation in the vagina. Immunology 84: 505-508, 1995.

7 - TABIBZADEH S.Cytokines and endometrial microenvironments. Sem Reprod Endocrinol 13: 133-141, 1995.

8 - KING A \& LOKE, YW. Uterine large granular lymphocytes: a possible role in embryonic implantation? Am J Obstet Gynecol 162: 308-310, 1990.

9 - BULMER JN. Immunology of the uterine decidual response. In: COULAM CB; FAULK WP \& MCINTYRE JA. Immunological obstetrics, W W Norton \& Company, New York, p. 245-255, 1992.

10 - SIMÓN C et al. Cytokines in implantation. Sem Reprod Endocrinol 13: 142-151, 1995.

11 - CHAOUAT G et al. Immuno-endocrine interactions in early pregnancy. Hum Reprod. 10: 55-59, 1995. Supplement 2.

12 - SIMÓN C et al. Interleukin-1 system crosstalk between embryo and endometrium in implantation. Hum Reprod 10: 43-54, 1995. Supplement 2.

13 - COULAM CB; FAULK WP; MCINTYRE JA. Overview of recurrent pregnancy loss. In: COULAM CB; FAULK WP \& MCINTYRE JA. Immunological obstetrics, W W Norton \& Company, New York, p. 245-255, 1992.

14 - De JONGH R, et al. The contribution of the immune system to parturition. Mediat Inflam 5: 173-182, 1996.

15 - STIRRAT GM. Recurrent spontaneous abortion. In: COULAM CB; FAULK WP \& MCINTYRE JA. Immunological obstetrics. W W Norton \& Company, London. p357-376, 1992.

16 - EDMONDS DK et al. Early embryonic mortality in women. Fertil Steril 38: 447-453, 1982.
17 - DUDLEY DJ \& BRANCH DW. New approaches to recurrent pregnancy loss. Clin Obstet Gynecol 32: 520-532, 1989.

18 - STIRRAT GM. Recurrent miscarriage I: definition and epidemiology. Lancet 336: 673-675, 1990.

19 - HILL JA. Immunological contributions to recurrent pregnancy loss. Clin Obstet Gynecol 6: 489-505,1992.

20 - VINARTIER A et al. Avortements d'origine immunologique. J Gynecol Obstet Biol Reprod 22: 339-350, 1993.

21 - KOMLOS L et al. Common HLA antigens in couples with repeated abortions. Clin Immunol Immunopathol 7: 330-335, 1977.

22 - OBER CL et al. Adverse effects of human leukocytes antigen-DR sharing on fertility: a cohort study in a human isolate. Fertil Steril 44: 227-232, 1985

23 - COWCHOCK FS \& SMITH JB. Predictors for live birth after unexplained spontaneous abortions: correlations between immunologic test results, obstetric histories, and outcome of next pregnancy without treatment. Am J Obstet Gynecol 167: 1208-1212, 1992

24 - CHRISTIANSEN OB et al. Placebo-controlled trial of active immunization with third party leukocytes in recurrent miscarriage. Acta Obtet Gynecol Scand 73: 261-268, 1994.

25 - STEACK T et al. HLA-DQA1 and HLA-DQB1 haplotypes in aborted fetuses and couples with recurrent spontaneous abortion. J Reprod Immunol 29: 95-104, 1995.

26 - HILL JA. Immunological mechanisms of pregnancy maintenance and failure: a critique of theories and therapy. Am J Reprod Immunol 22: 33-42, 1990.

27 - McINTYRE JA \& FAULK WP. Allotypic trophoblast-lyphocyte cross-reactive (TLX) cell surface antigens. Human Immunol 4: 27-35, 1982.

28 - MOWBRAY JF et al. Controlled trial of treatment of recurrent spontaneous abortion by immunization with paternal cells. Lancet 1: 931-933, 1985.

29 - CARP H JA et al. Immunization by paternal leukocytes for prevention of primary habitual abortion: results of a matched controlled trial. Gynecol Obstet Invest 29: 16-21, 1990.

30 - REGAN L \& BRAUDE PR. Is antiparternal cytotoxic antibody a valid marker in the management of recurrent abortion? Lancet 28: 1280, 1987.

31 - AOKI K et al. Preconceptional natural-killer-cell activity as a predictor of miscarriage. Lancet 345: 1340-1342, 1995.

32 - SOUZA SS. Avaliação de teste imunológicos em pacientes com aborto recorrente. Dissertação de Mestrado. Faculdade de Medicina de Ribeirão Preto-USP, Ribeirão Preto, p. 1-95, 1996.

33 - TAKAKUWA $\mathrm{K}$ et al. Influence of immunotherapy on the cellular immunity of unexplained recurrent aborts. J Reprod Immunol 20:153-163, 1991. 
34 - BEHAR E et al. Differential suppression activity induced by paternal leukocyte immunization in habitual abortion. Gynecol Obstet Invest 36: 202-207, 1993.

35 - FIZET D; BOUZGARROU R \& VEZON G. Lymphocyte immunization generates immunosupressive factors in women with recurrent abortions. Gynecol Obstet Invest 30: 8-11, 1990.

36 - CHRISTIANSEN OB et al. Placebo-controlled trial of active immunization with third party leukocytes in recurrent miscarriage. Acta Obtet Gynecol Scand 73: 261-268, 1994.

37 - HILL JA. T-helper 1-type immunity to trophoblast: evidence for a new immunological mechanism for recurrent abortion in women. Hum Reprod 10: 114-120, 1995.

38 - GLEICHER N. \& EL-ROEIY A. The reproductive autoimmune failure syndrome. Am J Obstet Gynecol 159: 223-227, 1988.

39 - GLEICHER N. Autoimmunity in obstetrics and gynecology. In: COULAM CB; FAULK WP \& MCINTYRE JA. Immunological obstetrics. W W Norton \& Company, London. p. 404-411, 1992.

40 - HUGHES GRV. Thrombosis, abortion, cerebral disease and lupus anticoagulant. Br Med J 287:1088-1089, 1983.

41 - JENG GT; SCOTT JR \& BURMEISTER LF. A comparison of meta-analytic results using literature vs individual patient data. JAMA 274: 830-836, 1995.

42 - FRASER EJ; GRIMES DA \& SCHULZ KF. Immunization as therapy for recurrent spontaneous abortion: a review and meta-analysis. Obstet Gynecol 82: 854-859, 1993.

43 - BUX J et al. Alloimmune neonatal neutropenia is a potencial side effect of immunization with leukocytes in women with recurrent spontaneous abortions. J Reprod Immunol 22: 299-302, 1992.

44 - CARP HJA et al. Congenital malformations after immunotherapy for habitual abortion: is there na increase? Gynecol Obstet Invest 36: 198-201, 1993.

45 - JENKINS S; OLIVE DL \& HANEY AF. Endometriosis: pathogenic implications of the anatomic distribution. Obstet Gynecol 67: 335-338, 1986.

46 - WEED JC \& ARGUEMBOURG PC. Endometriosis: can it produce na autoimmune response resulting in infertility? Clin Obstet Gynecol 23: 885-895, 1980.

47 - MATHUR S et al. Autoimmunity to endometrium and ovary in endometriosis. Clin Exp. Immunol 56: 259-266, 1982.
48 - HALME J; BECKER S \& HASKILL S. Altered maturation and function of peritoneal macrophages: a possible role in pathogenesis of endometriosis. Am J Obstet Gynecol 156: 783-787, 1987.

49 - SEMINO C et al. Role of major histocompatibility complex class I expression and natural killer-like T cells in the genetic control of endometriosis. Fertil Steril 64: 909-916, 1995.

50 - SOUZA SS et al. Aspectos imunológicos da infertilidade conjugal. Reprod Climat 11: 16-20, 1996.

51 - LOCKWOOD CJ \& RAND JH. The immunobiology and obstetrical consequences of antiphospholipid antibodies. Obstet Gynecol Survey 49: 432-441, 1994.

52 - STAGNARO-GREEN A et al. A prospective study of lymphocyte initiated immuno-supression in normal pregnancy: evidence of a T-cell etiology for post partum thyroid dysfunction. J Clin Endocrinol Metab 74: 645-653, 1992.

53 - GEVA E et al. Organ-specific autoantibodies are possible markers for reproductive failure: a prospective study in an in vitro fertilization embryo transfer programme. Hum Reprod 11: 1627-1631, 1996.

54 - STERN JE et al. Antisperm antibodies in women: variability in antibody levels in serum, mucus, and peritoneal fluid. Fertil Steril 58: 950-958, 1992

55 - NAZ RK \& MENGE AC. Antisperm antibodies: origin, regulation, and sperm reactivity in human infertility. Fertil Steril 61: 1001-1013, 1994.

56 - MARSHBURN PB \& KUTTEH WH. The role of antisperm antibodies in infertility. Fertil Steril 61: 799-811, 1994.

57 - HERGSHAGET A et al. The value of routine screening of female serum for antisperm antibodies in assisted reproductive technology cycles. Fertil Steril 61: 867-871, 1994.

58 - COULAM CB; MOORE B \& O'FALOON W. Investigating unexplained infertility. Am J Obstet Gynecol 158: 1374-1381, 1988.

59 - EGGERT-KRUSE $W$ et al. Antisperm antibodies in cervical mucus in an unselected subfertile population. Hum Reprod 8: 1025-1031, 1993.

60 - COLLINS JA et al. Frequency and predictive value of antisperm antibodies among infertile couples. Hum Reprod 8: 592-598, 1993.

61 - EGGERT-KRUSE $W$ et al. Circulating antisperm antibodies and fertility prognosis: a prospective study. Hum Reprod 4: 513-520, 1993. 